\title{
ABORDAGEM SOBRE COMPLEXO GENGIVITE-ESTOMATITE-FARINGITE EM GATO: RELATO DE CASO
}

\author{
FERREIRA, Guadalupe Sampaio ${ }^{1}$ \\ VASCONCELLOS, Amanda Leal de ${ }^{1}$ \\ MASSON, Guido Carlos Iselda Hermans ${ }^{2}$ \\ GALVÃ̃, André Luiz Baptista ${ }^{2}$ \\ LÉGA, Elzylene ${ }^{3}$ \\ PINTO, Mildre ${ }^{4}$
}

RESUMO: O Complexo gengivite-estomatite-faringite é uma síndrome comum em gatos caracterizada por intensa inflamação gengival e não-gengival na mucosa oral, ulceras ou proliferações ulcerativas graves do que as reações normalmente observadas à partir do acúmulo de placa dental, cálculo e progressão da doença periodontal. Gatos afetados mostram de ligeira disfagia a severa relutância em se alimentar. A diminuição na ingestão de alimentos leva à apatia e perda de peso progressiva. Essa síndrome pode afetar gatos de três a quinze anos, mas geralmente é observada em gatos com oito anos de idade. O tratamento periodontal mostra uma melhora de $80 \%$ na recuperação de gatos. Dessa forma, o presente trabalho tem a finalidade de relatar um caso dessa enfermidade, bem como, discutir sua possível patogenia e opções terapêuticas.

Palavras - chave: Gatos. Estomatite crônica. Infiltrado. Inflamatório

\section{APPROACH TO COMPLEX GINGIVITIS-STOMATITIS-PHARYNGITIS IN CAT: CASE REPORT}

SUMMARY: Complex gingivitis-stomatitis-pharyngitis is a common cat syndrome characterised by intense inflammation of gingival and non-gingival in the oral mucosa, ulcers or serious ulcerative proliferations than those normally observed for reactions from the accumulation of dental plaque and calculus and progression of periodontal disease. Affected cats show a mild to severe dysphagia and reluctance to eat. The decrease in food intake leads to apathy and progressive weight loss. This syndrome can affect cats from three to 15 years, but usually observed in cat under with eight years old. The periodontal treatment shows an improvement in the recovery of $80 \%$ of cats. Thus, this paper aims to report a case of this disease, as well discuss its possible pathogenesis and therapeutic options.

Keywords: Cats. Chronic stomatitis. Inflammatory. Infiltrate

\section{INTRODUÇÃO}

O complexo gengivite-estomatite-faringite (CGEF) é uma síndrome inflamatória grave que pode ser crônica e que acometem tanto os caninos, como os felinos. Caracterizam-se pela presença de ulcerações na mucosa oral ou na língua pelo contato com áreas de doença periodontal intensa. Nos felinos, a moléstia pode ser associada à progressão da inflamação para a região dos arcos glossopalatinos (região de encontro entre a mandíbula e a maxila, próximo à orofaringe) (GIOSO et al., 1999), recebendo diversos nomes, de acordo com a sua localização e o tipo de infiltrado inflamatório predominante, sendo

\footnotetext{
${ }^{1}$ Mestrandas em Medicina Veterinária da Faculdade de Ciências Agrárias e Veterinárias, - Universidade Estadual Paulista (FCAV/UNESP) - Jaboticabal-SP. Via de Acesso Prof. Paulo Donato Castelane, s/n 14884-900. Jaboticabal - SP - Brasil. Email: ferreira.guadalupe@gmail.com

${ }^{2}$ Doutorandos em Medicina Veterinária da Faculdade de Ciências Agrárias e Veterinárias, - Universidade Estadual Paulista (FCAV/UNESP) - Jaboticabal - SP - Brasil.

${ }^{3}$ Docente e Coordenadora do Curso de Graduação em Medicina Veterinária da Faculdade Dr. Francisco Maeda FAFRAM - Fundação Educacional de Ituverava-SP.

${ }^{4}$ Docente do Setor de Diagnóstico por Imagem do Centro Universitário Barão de Mauá - Ribeirão Preto-SP.
} 
assim, denominados de "estomatite crônica", "gengivite crônica", "estomatite /faucite felina", "gengivite/faringite plasmocitária", "estomatite felina intratável" e "gengivite/ estomatite linfocíticoplasmocitária" (DEBOWES, 2000; SCHORR-EVANS et al., 2003).

Esta doença é evidente na prática rotineira das clínicas em gatos asiáticos, em especial de raça siamês, não sendo notados prevalência com relação ao sexo, e os animais com idade média de oito anos são os mais acometidos (HENNET, 1997; GIOSO, 2007).

$\mathrm{O}$ fator desencadeante desta enfermidade e o processo fisiopatológico básico ainda não foram totalmente descobertos e podem diferir em cada caso (HOFMANN-APPOLLO et al., 2010). No entanto, acredita-se que possa estar relacionada ao acúmulo de placas bacterianas (Gram-negativos) a uma disfunção da resposta imunológica (HENNET, 1997). Ainda, os vírus do calicivírus felino (FCV) e o herpesvírus tipo 1 (FHV) são isolados com maior freqüência da cavidade oral de gatos com CGEF do que gatos sem estomatite, embora não haja comprovação de que esses agentes possam desencadear a doença (LOMMER; VERSTRAETE, 2003). Não obstante, os vírus da leucemia felina (FeLV) e da imunodeficiência viral felina (FIV) causam imunodepressão, favorecendo o aparecimento de infecções oportunistas e aumentando a gravidade das lesões na cavidade oral dos animais com CGEF (LOMMER; VERSTRAETE, 2003; LYON, 2005). Algumas pesquisas apresentaram Bartonella spp. como o fator associativo no CGEF em gatos (HARVEY, 1992).

A resposta imune frente à inflamação gengival crônica é realizada por meio da ação de anticorpos, sendo os plasmócitos e os linfóticos os primeiros grupos celulares em ação, proliferação e dominância neste tipo de processo inflamatório (HOFMANN-APPOLLO et al., 2010).

Dentre os sinais clínicos notados, se destacam a sialorreia, disfagia e inapetência, observando-se também dificuldade para se higienizar, deglutir, respirar, bem como, a hemorragia bucal e a emaciação, podem estar presentes. Na cavidade oral é comum observar lesões ulcerativas ou proliferativas nas regiões da faringe, mucosas alveolares, jugal e lingual. Podendo encontrar junto a essas alterações doença periodontal e lesões de reabsorção dentária (LYON, 2005; GIOSO, 2007).

Alguns autores dividem a GECF em vários estágios: gengivite marginal aguda, nos animais jovens, cuja apresentação é uma linha vermelha em redor dos dentes; outro estágio é a gengivite severa que vem acompanhada de estomatite nas áreas de contato com os pré-molares e molares em gatos de todas as idades; cita-se também a estomatite severa no arco glosso-palatino e faringe e, finalmente, a orofaringite que vem frequentemente acompanhada de lesões de reabsorção odontoclástica felina, tendo por fim a queda de dentes (SAN ROMAN et al., 1999).

Para o diagnóstico, dados obtidos pela anamnese, observações no exame físico da cavidade oral, e a verificação de sinais clínicos, na maioria das vezes são o suficiente para o fechamento do diagnóstico. Entretanto, para um diagnóstico conclusivo o exame histopatológico dessas lesões inflamatórias, juntamente com outros exames laboratoriais são métodos mais confiáveis (PEDERSEN, 1992).

No exame histopatológico é possível visibilizar infiltrado de plasmócitos e linfócitos, macrófagos e neutrófilos na submucosa (HENNET, 1997). Para melhor avaliação do paciente fica recomendado testes sorológicos para obtenção do prognóstico de doenças, recidivas e severidades das possíveis lesões virais (ELISA - Enzyme Linked Immuno Sorbent Assay) ou por Reação em Cadeia Polimerase (PCR Polymerase Chain Reaction) (HENNET, 2005; LYON, 2005).

O tratamento dessa afecção é complexo. Exige geralmente realização de tratamento periodontal, associado ao controle de placas bacterianas, antibioticoterapia e/ou imunossupressão com glicocorticoide, azatioprina, ciclosporina e terapia a laser (DIEHL; ROSYCHUK, 1993). A exodontia completa de todos os dentes é citada na literatura como um dos tratamentos que provém melhores resultados no controle (MEHL et al., 2003). Todavia, nenhum tratamento se mostrou totalmente eficaz em promover a cura 
desta enfermidade (HOFMANN-APPOLLO et al., 2010).

Frente à alta casuística e a complexidade da doença em felinos, o presente trabalho visa revisar a literatura disponível sobre o complexo gengivite-estomatite-faringite dos felinos, as prováveis causas etiológicas da doença, seus diagnóstico, bem como seus protocolos para tratamento.

\section{RELATO DE CASO}

Um felino, de raça siamês, macho, inteiro, com onze anos de idade, foi atendido com histórico clinico de inapetência, anorexia, emaciação, sialorreia e halitose. Ao exame físico foram observados linfonodos submandibulares levemente aumentados, presença de úlceras na cavidade oral, gengivite e cálculos dentários. No perfil hematológico e bioquímico (ureia e creatinina) não foram observadas alterações dignas de nota. Como medida terapêutica inicial o animal passou a receber metronidazol $25 \mathrm{mg} / \mathrm{kg}$ via oral, a cada 12 horas, durante duas semanas. Retornando após quinze dias para realizar tratamento periodontal. Com o animal sob anestesia geral (levopromazina, propofol e isoflurano), foram observadas lesões proliferativas, gengivite, cálculos dentários e mucosas hiperêmicas, friáveis e levemente hemorrágica na região das pregas glossopalatinas, sendo realizada a biópsia do material. Para o tratamento periodontal realizou-se limpeza com ultrassom, polimento com taça de borracha e pasta profilática. Após o procedimento o animal foi tratado com metronidazol na mesma posologia anterior e ampicilina $22 \mathrm{mg} / \mathrm{Kg}$ via oral a cada 12 horas, durante o período de duas semanas e gluconato de clorexidina a $0,12 \%$, a cada 12 horas na limpeza da cavidade oral. $\mathrm{O}$ animal evoluiu clinicamente bem no pós-operatório e apresentou remissão das lesões.

Os achados histopatológicos revelaram hiperplasia epitelial regular, espongiose, exocitose intensa de linfócitos e neutrófilos, além de áreas extensas de úlceras com depósitos de fibrina e infiltração de neutrófilos (Figura 1). O cório exibia faixa de intensa infiltração inflamatória composta principalmente por plasmócitos e linfócitos (Figura 2). Não se evidenciaram sinais de transformação neoplásica. O resultado do exame foi compatível com gengivite-estomatite linfoplasmocitária.

Figura 1. Fotomicrografia de área de exocitose apresentando espongiose (setas vermelhas). Coloração de Hematoxilina Eosina $(\mathrm{HE}),(\mathrm{Bar}=10 \mu \mathrm{m})$.

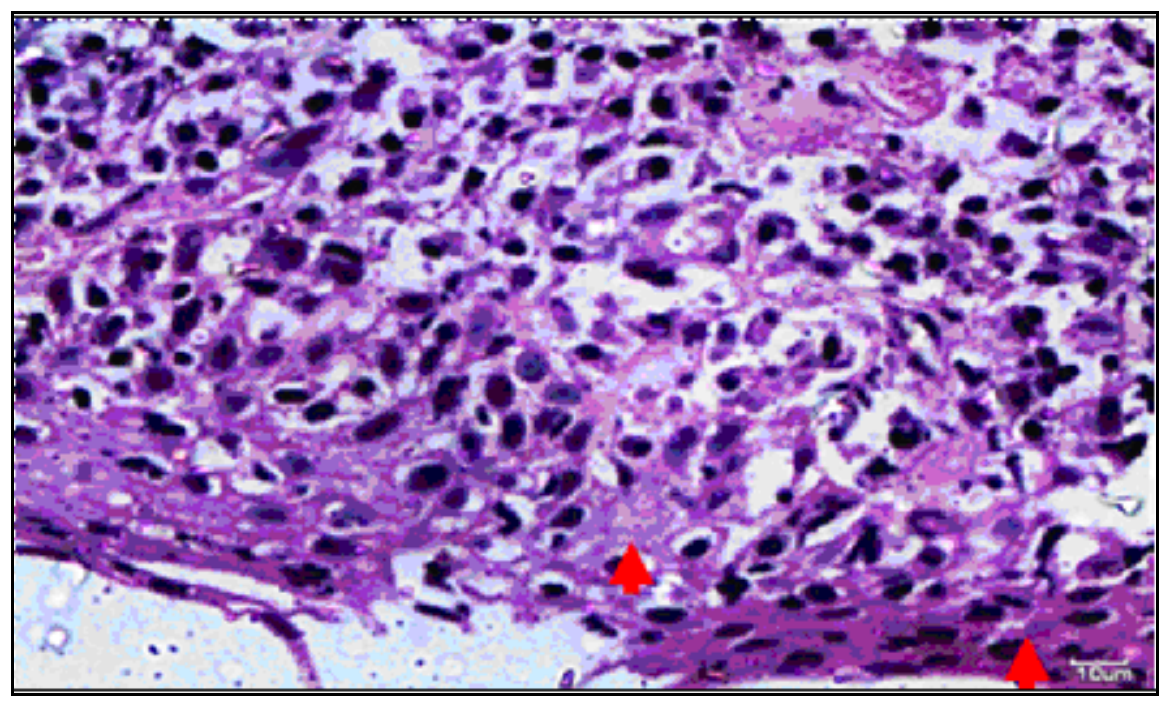


Figura 2. Fotomicrografia apresentando hiperplasia de epiderme (seta preta), área de ulceração (seta branca) e infiltrado inflamatório no cório (asterístico). Coloração de Hematoxilina Eosina (HE), (Bar = $100 \mu \mathrm{m})$.

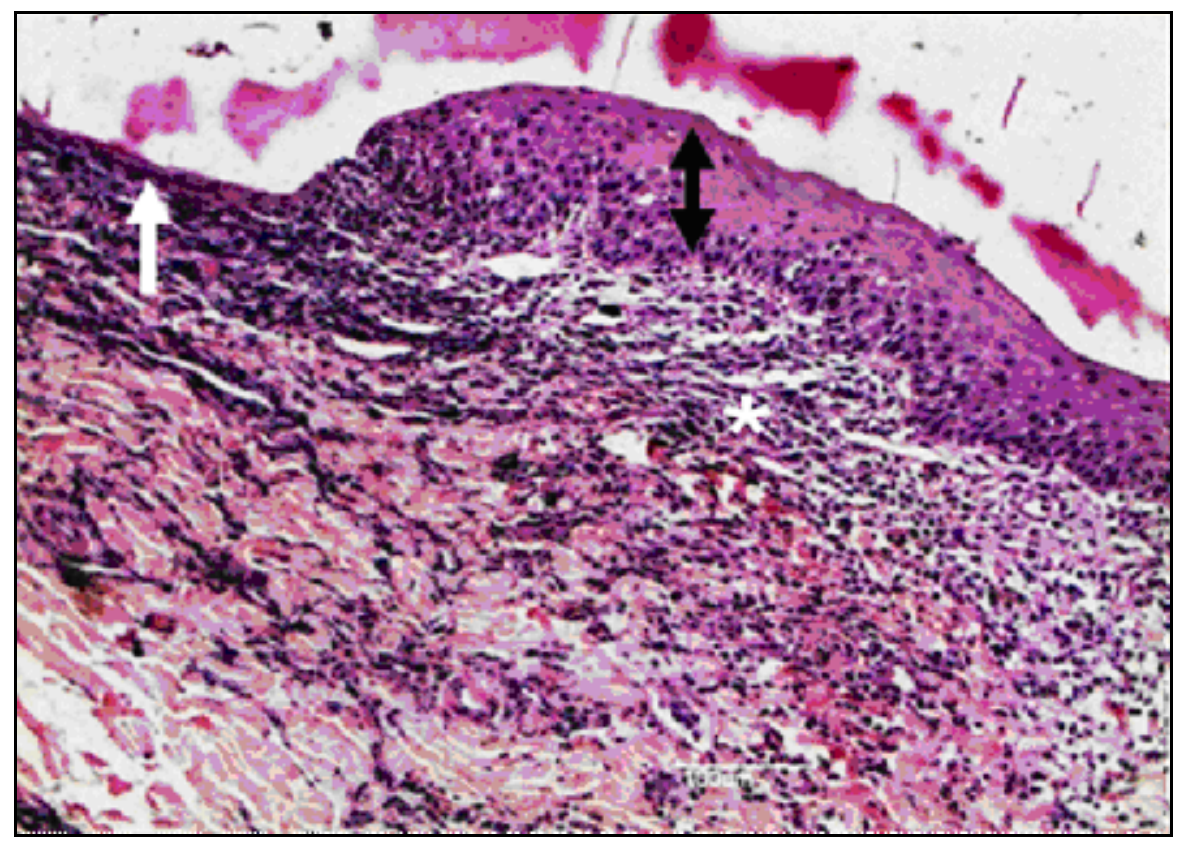

\section{DISCUSSÃO}

De acordo com Hennet (1997), Mehl et al. (2003) e Gioso (2007) os sinais clínicos observados na gengivite/estomatite linfocítico-plasmocitária em gatos são a halitose, sialorreia com estrias de sangue, disfagia, dor na cavidade oral, anorexia e perda de peso. No presente relato, o paciente manifestou sintomatologia clínica similar, corroborando com os achados dos autores. Ainda, Gioso (2007) e Hennet (1997) descrevem a maior ocorrência desta doença em gatos de raça siamês com idade avançada, semelhantes características observadas no presente relato de caso.

Segundo Hofmann-Appollo et al. (2010) gatos acometidos com esta moléstia devem ser avaliados nos perfis hematológicos e bioquímicos para melhor monitoramento e prognóstico do paciente. $\mathrm{O}$ animal de nosso estudo foi submetido a exames complementares não sendo constatadas alterações relevantes no perfil hematológico e bioquímico, similar aos descritos por Costa et al. (2007).

$\mathrm{Na}$ inspeção da cavidade oral podem-se notar lesões ulcerativas ou proliferativas nas regiões da faringe, do arco glossopalatino, da gengiva, das mucosas alveolar, jugal e lingual de acordo com Hennet (1997). Ainda, mucosas hiperêmicas, e cálculos dentários podem estar presentes conforme Costa et al (2007). No presente caso, também foi evidenciado lesões proliferativas, gengivite, cálculos dentários e mucosas hiperêmicas, friáveis e levemente hemorrágica na região das pregas glossopalatinas, semelhante aos achados com os autores supracitados. Segundo Harley e Gruffydd-Jones (2003) e Debowes (2000) nesta doença a presença crônica de ulceração e proliferação tecidual intensa na cavidade oral, a ocorrência de placa bacteriana e do cálculo dentário estão associadas a uma alteração da resposta imunológica do paciente, sendo sugerida como fator predisponente, fazendo o organismo a reagir de forma exacerbada.

Embora, o diagnóstico dessa enfermidade possa ser realizado pelos dados obtidos pela anamnese e exame da cavidade oral, o exame histopatológico deve ser considerado, pois além de ser conclusivo, estabelece a diferenciação com outras enfermidades conforme descrito por Costa et al. (2007). Ainda, Hofmann-Apollo et al. (2010) ressalta a importância deste tipo de exame, pois ele permite para os casos de gengivite - estomatite linfoplasmocitária a diferenciação de dois processos distintos: a síndrome 
inflamatória difusa incomum ou reação inflamatória gerada principalmente por plasmócitos, indicando uma reação imune. No presente relato o exame histopatológico foi realizado, sendo constatada a hiperplasia epitelial regular, espongiose, exocitose intensa de linfócitos e neutrófilos, além de áreas extensas de úlceras com depósitos de fibrina e infiltração de neutrófilos, ainda o cório exibia faixa de intensa infiltração inflamatória composta principalmente por plasmócitos e linfócitos, sendo o resultado do exame compatível com gengivite-estomatite linfoplasmocitária, corroborando com os descritos de Harvey (1992), Crystal (2004) e Hofmann-Appollo et al. (2010).

Como a etiologia desta moléstia é desconhecida, há suspeita da participação de fenômenos imunomediados como perpetuadores do processo conforme Harvey (1992) e Crystal (2004). O infiltrado inflamatório como linfócitos e plasmócitos vistos no caso de gengivite-estomatite linfoplasmocitária indicam um processo de caráter crônico, porém, não é um achado específico para determinar a causa, de acordo com Debowes (2000). O fator desencadeador de uma possível resposta imunológica no presente caso relatado pode ser devido à presença de grande quantidade de placas bacterianas na cavidade oral do paciente.

De acordo com Hofmann-Appollo et al. (2010) diversos estudos foram realizados na tentativa de se encontrar uma terapia adequada para esta enfermidade, admite-se hoje por uma associação entre tratamento clínico e cirúrgico como a medida terapêutica mais bem sucedida, no entanto, estes procedimentos não se mostram totalmente eficazes. Para o animal do presente relato primeiramente como tratamento foi administrado antibacterianos, apresentando uma melhora discreta como também descrito por Harvey (1992), porém, os melhores resultados foram apresentados após associação com tratamento periodontal, como já foi citado por Hennet (1997), Crystal (2004), Gioso (2007) e Hofmann-Appollo et al. (2010).

\section{CONCLUSÃO}

O complexo gengivite-estomatite-faringite, possui um caráter de grave cronicidade, cuja etiologia é ainda desconhecida no meio literário e seu tratamento além de complexo exige cooperação do proprietário.

\section{REFERÊNCIAS}

CRYSTAL, M. A. Gengivite-estomatite-faringite. In: NORSWORTHY, G.D.; CRYSTAL, M. A.; GRACE, S. F.; TILLEY,L. P. O Paciente felino, 2. ed. Barueri: Manole, p. 279-284, 2004.

COSTA, P. R. S.et al. Gengivite/estomatite linfocítico-plasmocitária em gatos: relato de quatro casos. Clínica Veterinária, ano XII, n. 66, p. 28-33, 2007.

DEBOWES, L. J. Feline stomatitis and faucitis. In: BONAGURA, J.D. Kirk's Current Veterinary Therapy XIII - Small Animal Practice. Philadelphia: Saunders, p. 600-602, 2000.

DIEHL, K.; ROSYCHUK, R.A. Feline gingivitis-stomatitis-pharyngitis. Veterinary Clinics North America Small Animal Practice, v.23, n.1, p.139-153, 1993.

GIOSO, M. A. Radiologia Odontológica en la Clínica de Pequeños Animales. Revista da AEVEDI, v. 2, n.4, p.121-130, 1999.

GIOSO, M. A. Odontologia para o clínico de pequenos animais 2.ed., São Paulo:Manole ,p. 170. 2007. 
GREENE, C. E. Gastrointestinal and Intra-abdominal infections. In GREENE, C. E. Infectious Diseases of the Dog and Cat, 2. ed. Philadelphia: saunders, cap. 89, p. 595-614,1998.

HARLEY, R.; GRUFFYDD-JONES, T.J.; DAY, M.J. Salivary and serum immunoglobulin levels in cats with chronic gingivostomatitis. Veterinary Record, n.152, p.125-129, 2003.

HARVEY, C.E. Feline Dentistry. Veterinary Clinics of North America: Small Animal Practice, v.22, n.6, p.1265-1496, 1992.

HENNET, P. Chronic gingivo-stomatitis in cats: long-term follow-up of 30 cases treated by dental extractions. Journal of Veterinary Dentistry, v.14, n.1, p.15-21, 1997.

HENNET, P. Relationship between oral calicivirus and herpesvirus carriage and "palatoglossitis" lesions. In: ANNUAL VETERINARY DENTAL FORUM \& WORLD VETERINARY DENTAL CONGRESS, 9, 2005, Orlando. Proceedings...Orlando: Academy of Veterinary Dentistry, American Veterinary Dental College, American Veterinary Dental Society, p.503, 2005.

HOFMANN-APPOLlO, F.; CARVALHO, V. G. G.; CIOSO, M. A. Complexo gengivite-estomatitefaringite dos felinos. Clínica Veterinária, ano XV, n. 84, p. 44-52, 2010.

LOMMER, M. J.; VERSTRAETE, F. J. M. Concurrent oral shedding of feline calicivirus and feline herpesvirus 1 in cats with chronic gingivostomatitis. Oral Microbiology immunology, v. 18, n.2, p. 131134, 2003.

LYON, K.F. Gingivostomatitis. Veterinary clinics of north america: small animal practice, v.35, p. 891-911, 2005.

MEHL, M.L.; KYLES, A.E.; CRAIGMILL, A.L. Disposition of cyclosporine after intravenous and multidose oral administration in cats. Journal of Veterinary Pharmacology and Therapeutics, v.26, n.5, p.349-354, 2003.

PEDERSEN, N. C. Inflammatory oral cavity diseases of the cat. Veterinary Clinics of North America: Small Animal Practice, v.22, n.6, p. 1323-1346, 1992.

SAN ROMAN, F. et al. Enfermidades inflamatórias da cavidade oral em pequenos animais In: ROMAN, F. San (ed.). Atlas de odontologia de pequenos animais. São Paulo: Manole, 1999. p. 127-142.

SHORR-EVANS, E.M.et al. An epizootic of highly virulent feline calcivirus disease in a hospital setting in New England. Journal of Feline Medicine and Surgery, v. 5, n.4, p. 217-226, 2003. 